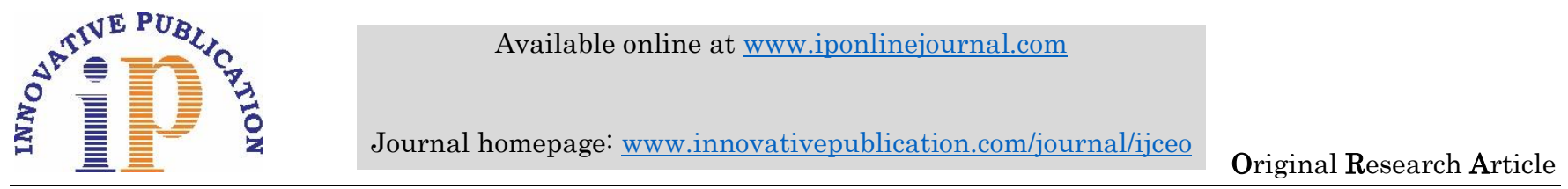

\title{
The visual outcome and surgical complications in posterior capsular rupture following cataract surgery with scleral fixated intraocular lens in tertiary care centre $-\mathrm{A}$ prospective study
}

\author{
Saravanan Jothi ${ }^{1 *}$, Kannan $\mathbf{M}^{2}$, Anupama Vinupal ${ }^{3}$ \\ ${ }^{\mathbf{1}}$ Assistant Professor, ${ }^{2}$ Senior Consultant, ${ }^{3}$ Resident, Dept. of Ophthalmology, ${ }^{\mathbf{1}, \mathbf{3}}$ Coimbatore Medical College Hospital, Coimbatore, Tamil \\ Nadu, ${ }^{2}$ Railway Hospital Perambur, Chennai, Tamil Nadu, India
}

\section{Article Info}

Received: $15^{\text {th }}$ April, 2019

Accepted: $24^{\text {th }}$ May, 2019

Published Online: $9^{\text {th }}$ September, 2019

Keywords: Aphakia, Inadequate posterior capsular support, Scleral fixated IOL.

\begin{abstract}
Aim: To analyse the complications as well as the long term functional and visual outcomes of anterior vitrectomy with scleral fixated posterior chamber intraocular lens implantation in patients with inadequate posterior capsular support.

Settings and Design: This was a prospective study done at Coimbatore Medical College Hospital, Coimbatore during the period of May 2016 to December 2017.

Materials and Methods: 30 eyes of 25 aphakic patients and 5 patients who had primary scleral fixated IOL implantation were included in the study. Anterior segment examination with slit lamp, preoperative visual acuity, intraocular pressure, fundus examination and IOL power calculation was done.

Results: Scleral fixation of IOL is a safe procedure with a success rate of $93 \%$ and most of the intraoperative and postoperative complications were minor. Postoperative best corrected visual acuity of $6 / 12$ and above was seen in $70 \%$ of patients.

Conclusion: Anterior vitrectomy with scleral fixated IOL implantation is a safe and effective procedure to correct aphakia in eyes without adequate posterior capsular support. Complications seen with anterior chamber IOL are not seen with SFIOL and dreaded complications like retinal detachment, suture lysis and infection were not encountered in our study. However precise determination of small differences in visual outcome and long-term complication rates would require a large prospective, randomized clinical trial.
\end{abstract}

\section{Introduction}

Aphakia was once considered a complication of cataract surgery. The crystalline lens, being responsible for approximately 30 percent of the total ocular dioptric power, aphakia results in marked visual disability. ${ }^{1}$

The development of safe and effective IOL's to eliminate the optical problem of aphakia is a feather in the cap for modern Ophthalmology. Modern posterior chamber IOL's are remarkably safe and provide excellent visual outcome after insertion into the capsular bag or sulcus, compared to earlier lens designs and fixation sites. ${ }^{2,3}$

Posterior capsular rupture is one of the dreaded complications of cataract surgery, and in cases where the IOL cannot be placed primarily due to PCR, renders the patient aphakic. PCR, thus is a complication that is better prevented as we can avoid subjecting the patient to a second surgery. In the presence of a posterior capsular tear during cataract extraction, the intraocular lens (IOL) can be placed in the ciliary sulcus if the capsular rim is available or in the capsular bag itself if the tear is small with optic capture technique. In situations where the posterior capsular tear is large or the capsular rim is unstable, scleral fixated intraocular lenses (SFIOL) or anterior chamber intraocular lenses (ACIOL) can be implanted. SFIOL's have certain advantages over ACIOL such as less corneal endothelial damage and minimising aniseikonia in contralateral eyes that are phakic or pseudophakic with a posterior chamber intraocular lens in place. SFIOL implantation also has the advantage of decreased incidence of other complications such as bullous keratopathy, uveitis and secondary glaucoma. Because of the availability of newer IOL's and safe techniques and when optimum vision with minimal complications is the expectation of the patient in present situation, ACIOL's are not in vogue in the present era and is rarely performed.

The main aim of our study is to analyse the functional and visual outcomes and to study the long-term complications of aphakic patients without adequate capsular support undergoing anterior vitrectomy with scleral fixated IOL implantation.

\section{Materials and Methods}

This is a prospective clinical study that was done at Coimbatore Medical College Hospital, Coimbatore. The

\footnotetext{
*Corresponding Author: Saravanan Jothi, Assistant Professor, Dept. of Ophthalmology, Coimbatore Medical College Hospital, Coimbatore, Tamil Nadu, India

Email: drsaravanan.j@gmail.com

http://doi.org/10.18231/j.ijceo.2019.071
} 
study included 30 eyes of which 25 were aphakic patients who underwent secondary SFIOL implantation and 5 patients who underwent primary SFIOL implantation. The patients were followed up for a period of 1 year from May 2016 to December 2017.

Patient details that were collected include name, age, sex, duration of aphakia, history of trauma, history of past ocular surgeries, presence of diplopia, and history of co morbid systemic diseases.

Routine anterior segment examination using slit lamp was done. Presence of aphakia, status of posterior capsule, presence of vitreous strands in the pupillary area and anterior chamber, pupillary peaking, posterior synechiae and presence of peripheral iridectomy were assessed. Preoperative uncorrected and best corrected visual acuity was recorded using Snellen's distant visual acuity chart. Intraocular pressure was recorded for all cases using Noncontact tonometer. Fundus examination was done by using IDO. Keratometry was done with Bausch and Lomb keratometer. Axial length was calculated using A scan. IOL power was calculated using SRK formula with 118.2 as A constant for scleral fixated IOL's. Patients with unilateral aphakia / unilateral lens subluxation, with a minimum interval of six weeks between the primary procedure and secondary IOL implantation, BCVA better than or equal to $6 / 24$ and a normal fundus were included in the study. Patients with bilateral aphakia, patients with BCVA worse than $6 / 24$, those with posterior segment pathologies affecting vision and one-eyed patients were excluded from the study.

Preoperative pupillary dilation was done and surgery was done under peribulbar anaesthesia. Anterior vitrectomy was done using automated $23 \mathrm{G}$ vitrectomy cutter and SFIOL implantation was done using the Railroad technique. ${ }^{4,5}$ By this technique 10-0 polypropylene suture was passed through one scleral flap and taken out through the other side with the help of a 26-gauge needle. The suture was taken out from the eye through the superior scleral tunnel using sinskey hook. The two suture ends were tied to the eyelets of SFIOL haptics and was implanted into the posterior chamber after centring and then sutured.

Postoperatively, all the patients were given topical weeks. If postoperative inflammation was severe or anticipated to be severe, then $1 \%$ prednisolone with ofloxacin eye drops was given.

On postoperative day 1, wound approximation, corneal status, anterior chamber depth and reaction, IOL centration was assessed and IOP was recorded by NCT. On postoperative day 2 , in addition, fundus examination was performed with IDO to rule out posterior complications. Follow up examination at 1 month, 6 months and 1 year included visual acuity using Snellen's distant vision chart, IOP measurement by NCT, and assessment of corneal status, anterior chamber depth and reaction, IOL centration, IOL surface examination, fundus examination and presence of any other associated complications. ofloxacin and dexamethasone eye drops for a period of 6

\section{Results}

Out of the 30 patients who underwent SFIOL implantation during the study period, 10 were males and 20 were females. Mean age was found to be 65 years. Twenty-five aphakic patients underwent secondary SFIOL implantation accounting for $83 \%$ of total and 5 patients underwent primary SFIOL implantation accounting for $17 \%$. Among the 5 patients taken up for primary SFIOL suturing, two had traumatic subluxation of cataractous lens.

The mean interval between the initial cataract surgery and the secondary SFIOL implantation was 14.25 weeks (ranging from 6 to 72 weeks). Intraoperative complications included vitreous haemorrhage in 2 patients, suture breakage while tying the knot with repeating of procedure from the beginning in 3 patients and uneventful surgery in the rest.

Immediate postoperative complications included $\mathrm{AC}$ flare and cells in 10 cases (33\%), striate keratopathy in 4 cases $(13 \%)$ and corneal edema in 4 cases $(13 \%)$. (Table 1 and 2)

Visual acuity and complication profile were assessed at 1 month, 6 months and 1 year post operatively. (Table $3,4,5,6)$

Late postoperative complications were persistent uveitis in 2 cases (7\%), cystoid macular edema in 2 cases (7\%), vitreous prolapse into anterior chamber in 1 case $(3 \%)$, IOL decentration in 1 case (3\%). (Table 5 and 6 )

Table 1: Visual outcome following SFIOL after 24hrs

\begin{tabular}{|c|c|c|}
\hline Visual acuity & No. of cases & Percentage \\
\hline $6 / 6$ & 0 & 0 \\
\hline $6 / 9$ & 3 & 10 \\
\hline $6 / 12$ & 11 & 37 \\
\hline $6 / 18$ & 9 & 30 \\
\hline $6 / 24$ & 4 & 13 \\
\hline $6 / 36$ & 0 & 0 \\
\hline $6 / 60$ and less & 3 & 10 \\
\hline
\end{tabular}

Table 2: Complications following SFIOL after 24hrs

\begin{tabular}{|c|c|c|}
\hline Complication & No. of cases & Percentage \\
\hline Wound leak & 0 & 0 \\
\hline Striate Keratopathy & 4 & 13 \\
\hline Corneal edema & 4 & 13 \\
\hline Hyphema & 1 & 3 \\
\hline Shallow AC & 0 & 0 \\
\hline Ac flare and cells & 10 & 33 \\
\hline Pupillary capture & 0 & 0 \\
\hline IOL decentration & 1 & 3 \\
\hline IOP > 30mm Hg & 2 & 7 \\
\hline Vitreous haemorrhage & 2 & 7 \\
\hline
\end{tabular}

Table 3: Visual outcome following SFIOL after 1 month

\begin{tabular}{|c|c|c|}
\hline Visual acuity & No. of cases & Percentage \\
\hline $6 / 6$ & 1 & 3 \\
\hline $6 / 9$ & 3 & 10 \\
\hline $6 / 12$ & 14 & 47 \\
\hline $6 / 18$ & 6 & 20 \\
\hline
\end{tabular}




\begin{tabular}{|c|c|c|}
\hline $6 / 24$ & 3 & 10 \\
\hline $6 / 36$ & 0 & 0 \\
\hline $6 / 60$ and less & 3 & 10 \\
\hline
\end{tabular}

Table 4: Complications following SFIOL after 1 month

\begin{tabular}{|c|c|c|}
\hline Complication & No. of cases & Percentage \\
\hline Fibrin & 0 & 0 \\
\hline Corneal edema & 3 & 10 \\
\hline Hyphema & 0 & 0 \\
\hline Anterior uveitis & 5 & 17 \\
\hline Pupillary capture of IOL & 0 & 0 \\
\hline IOL decentration & 1 & 3 \\
\hline IOP > 30 mm Hg & 2 & 7 \\
\hline Vitreous haemorrhage & 2 & 7 \\
\hline
\end{tabular}

Table 5: Visual outcome following SFIOL after 1 year

\begin{tabular}{|c|c|c|}
\hline Visual acuity & No. of cases & Percentage \\
\hline $6 / 6 /$ & 1 & 3 \\
\hline $6 / 9$ & 7 & 23 \\
\hline $6 / 12$ & 13 & 44 \\
\hline $6 / 18$ & 4 & 13 \\
\hline $6 / 24$ & 2 & 7 \\
\hline $6 / 36$ & 1 & 3 \\
\hline $6 / 60$ or less & 2 & 7 \\
\hline
\end{tabular}

Table 6: Complications following SFIOL after 1 year

\begin{tabular}{|l|c|c|}
\hline \multicolumn{1}{|c|}{ Complication } & $\begin{array}{c}\text { No. of } \\
\text { cases }\end{array}$ & Percentage \\
\hline Glaucoma & 0 & 0 \\
\hline Pupil deformation & 0 & 0 \\
\hline Persistent uveitis & 2 & 7 \\
\hline Cystoid macular edema & 2 & 7 \\
\hline $\begin{array}{l}\text { Vitreous prolapse into anterior } \\
\text { chamber }\end{array}$ & 1 & 3 \\
\hline IOL decentration & 1 & 3 \\
\hline Suture erosion & 0 & 0 \\
\hline IOL surface debris & 1 & 3 \\
\hline
\end{tabular}

\section{Discussion}

Secondary intraocular lens implantation is defined as the insertion of an IOL into an eye that has been rendered aphakic by prior cataract extraction by any method, or by an exchange of IOL, which is a special case of secondary IOL implantation.

SFIOL's have the advantages of decreased risk of pupillary block and secondary glaucoma; little or no contact of IOL with the iris, thereby decreasing the risk of iritis, ${ }^{6}$ pigment dispersion and cystoid macular edema. The risk of pseudophakodonesis is reduced as the sulcus location of the IOL approximates the normal anatomical position of the crystalline lens. ${ }^{7}$ SFIOL's are appropriate for all age groups including children ${ }^{8-10}$ because they are more likely than ACIOL's to accommodate the growing eye.

In our prospective study of 30 cases done from May 2016 to December 2017, 25 cases were taken up for secondary suturing of scleral fixated IOL.
Five cases were taken up for primary suturing of SFIOL of which two were traumatically subluxated cataractous lens and the other three had a large capsular tear during routine small incision cataract surgery. The mean follow up period was 12 months. The best corrected visual acuity of $6 / 12$ and above was seen in 21 cases $(70 \%) .{ }^{11}$

Two cases of traumatically subluxated lens who underwent primary SFIOL fixation had a BCVA at 1 year of $6 / 60$ and 6/36 respectively. They had mild persistent uveitis. The visual acuity was better than the preoperative best corrected vision.

IOL decentration was observed in one case, but did not affect the visual acuity significantly as it was minimal.

Vitreous prolapse into anterior chamber was noted in one case. Cystoid macular edema was seen in one case who had a vitreous haemorrhage in the immediate postoperative period which cleared after 6 months. The BCVA was $6 / 60$.

None of the cases had retinal detachment, lens tilt or endophthalmitis. No suture erosion was observed in our study as the suture knot was buried under the scleral flap.

\section{Conclusion}

In our study of 30 patients who underwent anterior vitrectomy with scleral fixated posterior chamber intraocular lens implantation we concluded that the surgery is a safe and effective procedure to correct aphakia in eyes without capsular support. ${ }^{12}$ The most dreaded complications of retinal detachment and suture lysis were not encountered in our study during the follow up period of one year. Discomfort and anisekonia from wearing aphakic spectacles can be avoided and the devastating complications associated with anterior chamber intraocular lens implantation such as bullous keratopathy, secondary glaucoma and uveitis are not seen with SFIOL implantation as there is anatomical placement of the IOL in the posterior chamber. ${ }^{13-15}$ However, precise determination of small differences in visual outcome and long-term complications of SFIOL implantation will require a large prospective, randomised clinical trial. ${ }^{16}$

\section{Source of Funding: None.}

\section{Conflict of Interest: None.}

\section{References}

1. Steinert RF. Surgical alternatives in monocular aphakia. Focal points 1990: Clinical modules for Ophthalmologists, Vol.8 American Academy of Ophthalmology, 1990, p1

2. Waring GO III. The 50-year epidemic of pseudophakic corneal edema [editorial]. Arch Ophthalmol 1989;107: 657-9

3. Apple DJ, Mamalis N, Loftfield K. Complications of intraocular lenses. A historical and histopathological review. Surv Ophthalmol 1984;29:1-54.

4. Steinert RF, Arkin MS. Secondary intraocular lenses. In: Steinert RF, ed. Cataract surgery: techniques, complications and management, $2^{\text {nd }}$ ed. Philadelphia: Saunders 2004:434

5. Madanagopalan VG, Sen P, Prabu B, Scleral-fixated intraocular lenses, J Ophthalmic Sci Res. 2018;56(4):23743. 
6. Apple DJ, Mamalis N, Loftfield K. Complications of intraocular lenses. A historical and histopathological review. Surv Ophthalmol 1984;29:1.

7. Binkhorst CD: Corneal and retinal complications after cataract extraction: The mechanical aspect of endophthalmodonesis. Ophthalmol 1980;87:609.

8. Sharpe MR, Biglan AW, Gerontis CC: Scleral fixation of posterior chamber intraocular lenses in children. Ophthalmic Surg Lasers. 1996;27:337.

9. Buckley EG: Scleral fixated (sutured) posterior chamber intraocular lens implantation in childred. J AAPOS. 1999;3:289.

10. Mittelviefhaus H, Mittelviefhaus K, Gerling J: Transscleral suture fixation of posterior chamber intraocular lenses in children under 3 years. Graefes Arch Clin Exp Ophthalmol 2000;238:143.

11. Chang JH, Lee JH. Long term results of implantation of posterior chamber intraocular lens by sulcus fixation. Korean $J$ Ophthalmol. 1991;5:42-6.

12. Yalniz-Akkaya Z, Burcu A, Uney GO, Abay I, Eksioglu U, Acar MA et al, Primary and Secondary Implantation of
Scleral-Fixated Posterior Chamber Intraocular Lenses in Adult Patient. Middle East Afr J Ophthalmol 2014;21(1):44-9.

13. Lyle WA, Jin JC. Secondary intraocular lens implantation: anterior chamber vs posterior chamber lenses. Ophthalmic Surg. 1993;24:375-81

14. Belluci R, Pucci S, Morselli S, Bonomi L. Secondary implantation of angle supported anterior chamber and scleral fixated posterior chamber intraocular lenses. J Cataract Refract Surg 1996;22:247-52

15. Kumar S, Singh S, Singh G, Rajwade NS, Sushank A. Bhalerao, Singh V et al. Visual outcome and complications of various techniques of secondary intraocular lens. Oman $J$ Ophthalmol 2017;10(3):198-204.

16. Luk ASW, Young AL, Cheng LL Long-term outcome of scleral-fixated intraocular lens implantation. Br J Ophthalmol. 2013;97:1308-11.

How to cite this article: Jothi S, Kannan M, Vinupal A. The visual outcome and surgical complications in posterior capsular rupture following cataract surgery with scleral fixated intraocular lens in tertiary care centre - A prospective study. Indian J Clin Exp Ophthalmol. 2019;5(3):297-300. 